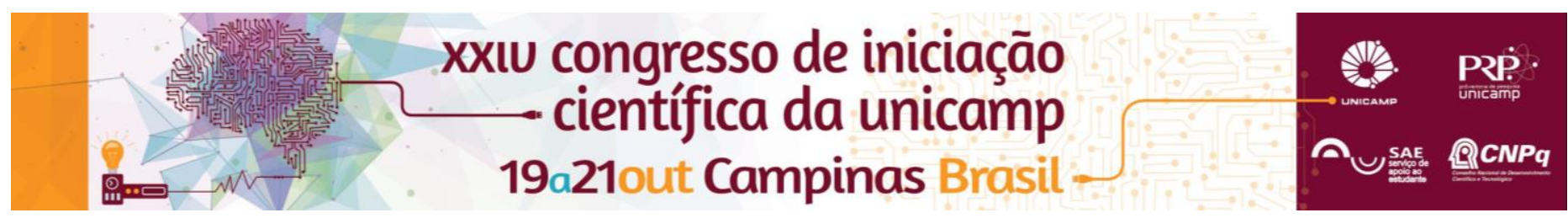

\title{
DESENVOLVIMENTO DE PLACAS DE FIXAÇÃO ÓSSEAS COM GRADIENTE DE RIGIDEZ BASEADO EM LIGAS DE TITÂNIO BETA METẢESTÁVEL
}

\author{
Lucas Pergolizzi de Castro Sousa*, Dalton Daniel de Lima, Rubens Caram Jr.
}

\section{Resumo}

O objetivo deste trabalho é desenvolver uma placa de fixação de fratura óssea baseada em ligas de titânio do tipo beta metaestável. É meta obter um dispositivo que permita estabilizar a fratura óssea, mas também evitar o desenvolvimento de blindagem de tensões no osso implantado, que podem levar a degeneração óssea. $O$ resultados indicam que placas com gradientes de rigidez podem ser obtidas por meio de tratamentos térmicos de ligas de Ti.

\section{Palavras-chave:}

Placa de fixação de fratura óssea, Ligas de Titânio $\beta$ Metaestável, Gradiente de Rigidez.

\section{Introdução}

As ligas de $\mathrm{Ti}$ são utilizadas em dispositivos ortopédicos para reparo de fraturas ósseas. Essa aplicação se deve ao seu comportamento mecânico único, alta resistência à corrosão e elevada biocompatibilidade. Placas de fixação de fratura óssea devem ser suficientemente rígidas para evitar instabilidade mecânica no local da fratura e também, evitar a blindagem de tensões mecânicas no osso implantado, que podem resultar em degradação óssea. De acordo com estudos anteriores ${ }^{1}$, placa com gradiente de rigidez é capaz de respeitar essas condições. Este trabalho tem como meta desenvolver placas de fixação óssea a partir de ligas de Ti $\beta$ metaestável com gradiente de rigidez obtido por meio da aplicação de tratamentos de envelhecimento às amostras. A figura 1 mostra uma placa de fixação de fratura óssea, com regiões exibindo diferentes módulos de elasticidade $(\mathrm{E})$.
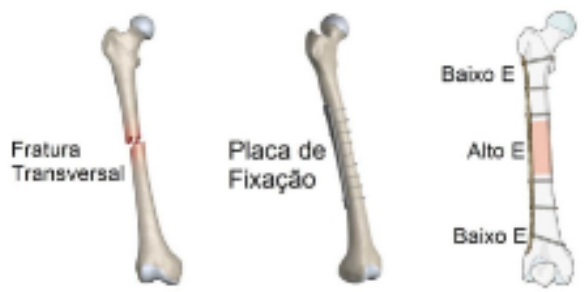

Figura 1. Esquema ilustrativo da placa de fixação óssea e das regiões com diferentes módulos de elasticidade ${ }^{2}$.

\section{Resultados e Discussão}

A liga de Ti usada nesse estudo é baseada no sistema Ti-Nb, com adições de elementos supressores de fase $\omega$. Essa liga foi produzida em forno de fusão a arco, homogeneizada a $1000^{\circ} \mathrm{C}$ por $24 \mathrm{~h}$. Em seguida, as amostras foram laminadas a quente e resfriadas rapidamente em água. Ao final desse processo, a microestrutura das amostras é constituída apenas pela fase $\beta$. Finalmente, com 0 intuito de precipitar a fase $\alpha$, responsável pelo aumento da rigidez, as amostras são submetidas a aquecimento localizado por indução eletromagnética à temperatura de $500^{\circ} \mathrm{C}$, por 1 hora, como mostrado na figura 2. Tal procedimento permite obter microestrutura diferenciada ao longo da amostra, o que gera gradiente de rigidez ao longo da mesma. As extremidades da amostra exibem microestrutura formada pela fase $\beta$, enquanto que o centro da amostra exibe as fases $\alpha$ e $\beta$. Como a fase $\alpha$ apresenta alto módulo de elasticidade e a fase $\beta$ baixo módulo, tem-se uma placa com alto módulo na região central e baixo módulo nas regiões extremas. É possível obter módulo de elasticidade de $60 \mathrm{GPa}$ nas extremidades da placa e 100 GPa na região central da mesma. A figura 3 apresenta microestruturas típicas de amostras após o resfriamento em água (a) e após o envelhecimento (b).

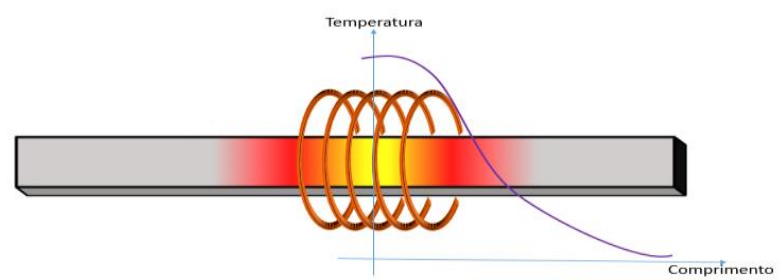

Figura 2. Esquema de processo de envelhecimento por indução localizada em placa.

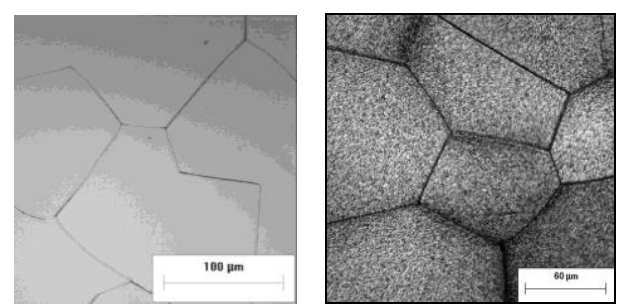

Figura 3. Microestruturas típicas da liga de Ti após (a) solubilização e resfriamento em água e após tratamento térmico de envelhecimento.

\section{Conclusões}

Os resultados obtidos indicam que é possível impor gradiente de rigidez ao longo da placa de fixação óssea.

\section{Agradecimentos}

Os autores agradecem as instituições de fomento à pesquisa PIBIC, FAPESP e CNPq pelo auxílio financeiro.

\footnotetext{
1 V.K. Ganesh, K. Ramakrishna and D.N. Ghista, Biomechanics of bone-fracture fixation by stiffness-graded plates in comparison with stainless-steel plates, BioMedical Engineering OnLine 2005, 4:46, 2005.

2 LIMA, D. D. Componentes com Gradientes Funcionais para Aplicação em Ortopedia Obtidos por Manufatura Aditiva de Ligas de Titânio. 2015. 84 p. Campinas: Faculdade de engenharia mecânica, Universidade estadual de Campinas. Dissertação (Mestrado), 2015
} 